\title{
Heterologous Biosynthesis and Genomics-Driven Derivatization of Fungal Bioactive Sesterterpenoid Variecolin
}

\author{
Dexiu Yan, ${ }^{+}$Jemma Arakelyan, ${ }^{+}$Teng Wan, ${ }^{+}$Tsz Ki Chan, ${ }^{+}$Dohyun Ahn, ${ }^{+}$Tsz Kiu Cheung, ${ }^{+}$Ho Ching Chan, ${ }^{+}$ \\ Inseo Choi, ${ }^{+}$Pui Yi Ho, ${ }^{+}$Feijun Hu, ${ }^{+}$Yujeong Kim, ${ }^{+}$Hill Lam Lau, ${ }^{+}$Ying Lo Law, ${ }^{+}$Chi Seng Leung, ${ }^{+}$Ritvik \\ Raina, ${ }^{\S}$ Chun Yin Tong, ${ }^{\dagger}$ Kai Kap Wong, ${ }^{+}$Wing Lam Yim, ${ }^{\dagger}$ Richard Y. C. Kong, ${ }^{*,+}$ Maria V. Babak, ${ }^{*,+}$ and Yudai \\ Matsuda $^{*,+}$ \\ ${ }^{+}$Department of Chemistry, City University of Hong Kong, Tat Chee Avenue, Kowloon, Hong Kong SAR, China \\ ${ }^{\S}$ Department of Biomedical Engineering, City University of Hong Kong, Tat Chee Avenue, Kowloon, Hong Kong SAR, China
}

\begin{abstract}
The biosynthetic gene cluster of fungal bioactive sesterterpenoids, variecolin (1) and variecolactone (2), was identified in $A s$ pergillus aculeatus ATCC 16872. Heterologous production of 1 and 2 was achieved in Aspergillus oryzae by expressing the sesterterpene synthase VrcA and the cytochrome P450 VrcB. Intriguingly, the replacement of VrcB with homologous P450s from other fungal terpenoid pathways yielded three new variecolin analogues, one of which exhibited potent anticancer activity comparable to that of 1 .
\end{abstract}

Sesterterpenoids, derived from five molecules of isoprene $\left(C_{5}\right)$ units, are one of the classes of terpenoids, which are widely distributed but relatively rare in nature. ${ }^{1}$ Fungi are prolific producers of sesterterpenoids with a wide range of biological activities, as represented by ophiobolin A that displays a potent anticancer activity. ${ }^{2}$ Since the discovery and characterization of the first sesterterpene synthase in $2013,{ }^{3}$ biosynthetic pathways of several fungal sesterterpenoids have been elucidated to date. ${ }^{4}$ Furthermore, a number of new sesterterpenoids have been obtained by genome mining approach targeting unexploited fungal sesterterpene synthase genes. ${ }^{5}$ All of the characterized fungal sesterterpene synthases are chimeric proteins consisting of C-terminal prenyltransferase (PT) and N-terminal terpene cyclase (TC) domains. The PT domain is responsible for the synthesis of $\mathrm{C}_{25}$ geranylfarnesyl pyrophosphate (GFPP) using one molecule of dimethylallyl pyrophosphate (DMAPP) and four molecules of isopentenyl pyrophosphate (IPP) as substrates, whereas the TC domain performs ionization-initiated (class I) cyclization of GFPP to afford a cyclized product. ${ }^{6}$ The cyclized product could then undergo tailoring reactions to be converted into a final sesterterpenoid. Interestingly, the biosynthetic gene clusters of fungal sesterterpenoids are relatively compact compared with those for other fungal secondary metabolites, suggesting that fungal sesterterpenoid biosynthesis could easily be engineered to generate diverse analogues.

Variecolin (1) is a tetracyclic sesterterpenoid originally isolated from the fungus Aspergillus variecolor MF138 as an angiotensin II receptor binding inhibitor. ${ }^{7}$ Subsequently, 1 and its congeners, such as variecolactone (2) and emericolin A (3), have also been obtained from several different fungi and have proven to possess diverse and potent biological activities (Figure 1A), ${ }^{8}$ including antifungal, ${ }^{8 a}$ immunomodulatory, ${ }^{8 \mathrm{c}}$ CCR5 inhibitory, ${ }^{8 \mathrm{~d}}$ antibacterial, ${ }^{8 \mathrm{e}}$ antimalarial, ${ }^{8 f}$ and anticancer ${ }^{8 f}$ activities. The biological activities and the intriguing molecular framework of $\mathbf{1}$ have also inspired synthetic chemists to attempt the synthesis of $1{ }^{9}$ however, no total synthesis of 1 has been achieved, making 1 a challenging synthetic target. Furthermore, despite the recent rapid advance in biosynthetic studies on fungal sesterterpenoids, the biosynthetic genes for $\mathbf{1}$ have not been reported. Thus, identification and characterization of the biosynthetic gene cluster of $\mathbf{1}$ would facilitate efficient production and structural modification of this medicinally important molecule in biocatalytic or synthetic biology approaches.

In this study, to achieve the total biosynthesis and derivatization of variecolin (1), we first identified the biosynthetic gene cluster of 1 in Aspergillus aculeatus, and then succeeded in the heterologous production of 1 , which requires the terpene synthase $\operatorname{VrcA}$ and the cytochrome $\mathrm{P} 450$ monooxygenase $\mathrm{VrcB}$. We also obtained three new variecolin analogues by utilizing a series of $\mathrm{VrcB}$ homologues. Finally, we evaluated the biological activity of the obtained molecules, and found that one of the unnatural variecolin analogues displays potent anticancer activity. 
(A)

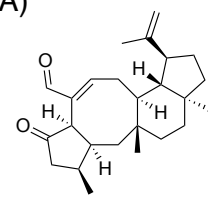

variecolin (1)

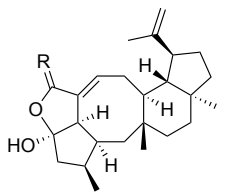

variecolactone (2): $\mathrm{R}=\mathrm{O}$ variecolol: $\mathrm{R}=\mathrm{H}_{2}$

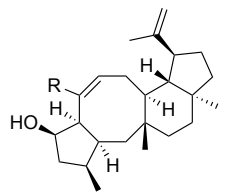

emericolin $\mathrm{A}(\mathbf{3}): \mathrm{R}=\mathrm{CHO}$ emericolin $\mathrm{B}: \mathrm{R}=\mathrm{CH}_{2} \mathrm{OH}$ emericolin $\mathrm{C}: \mathrm{R}=\mathrm{CH}_{3}$
(B)

The vrc cluster from Aspergillus aculeatus ATCC 16872 ca. $11.8 \mathrm{~kb}$

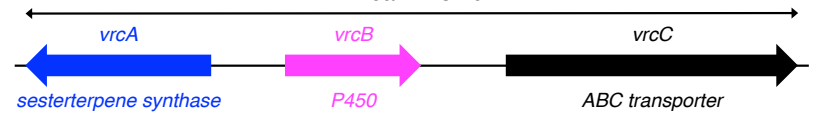

(C)


Figure 1. (A) Structures of variecolin (1) and its selected analogues. (B) Schematic representation of the vrc cluster. (C) Predicted biosynthetic pathway of 1 .

To discover the biosynthetic gene cluster of variecolin (1), we examined the genome sequence of $A$. aculeatus ATCC 16872 (CBS 172.66), ${ }^{10}$ since $A$. aculeatus is one of the known producers of $1 .{ }^{8 f}$ The investigation of the $A$. aculeatus genome revealed the presence of two homologous proteins of known sesterterpene synthases. Since the backbone skeleton of $\mathbf{1}$ is expected to be synthesized in a highly similar manner to the generation of astellifadiene, ${ }^{5 \mathrm{~b}}$ the terpene synthase for the variecolin biosynthesis should display high sequence identity with the astellifadiene synthase (EvAS). One of the possible sesterterpene synthases in $A$. aculeatus exhibits $65 \%$ amino acid sequence identity with EvAS, and therefore, we reasoned that the enzyme is involved in the variecolin pathway. In the flanking region of this terpene synthase gene, we observed the existence of cytochrome $\mathrm{P} 450$ monooxygenase and ATP-binding cassette $(\mathrm{ABC})$ transporter genes, which apparently form a gene cluster along with the terpene synthase gene (Figure 1B). The gene cluster, which is hereby designated as the vrc cluster, is conserved among several fungi, including another known producer of 1, Aspergillus japonicus ${ }^{11}$ further indicating the involvement of the vrc cluster in the variecolin biosynthesis. On the basis of the gene cluster information, the biosynthetic route leading to 1 could be predicted as follows; the sesterterpene synthase VrcA first yields a hydrocarbon with the variecolin scaffold, which then undergoes multiple oxidations catalyzed by the P450 VrcB to afford 1 (Figure 1C).

To analyze the function of the vrc cluster, we next heterologously expressed the terpene synthase gene $\operatorname{vrc} A$ in the fungus Aspergillus oryzae NSAR $1,{ }^{12}$ which is a powerful platform for the heterologous reconstitution of fungal metabolite biosynthesis. ${ }^{13}$ The metabolites derived from the $A$. oryzae transformant were analyzed by GC-MS. As a result, a new product 4 with $\mathrm{m} / z 340[\mathrm{M}]^{+}$, which corresponds to a sesterterpene hydrocarbon, was detected only in the transformant harboring $\operatorname{vrc} A$ (Figure $2 \mathrm{~A}$ ). After the large-scale cultivation of the transformant, 4 was successfully isolated and subjected to MS and NMR analysis for structural characterization. The HR-APCI-
MS analysis determined the molecular formula of 4 as $\mathrm{C}_{25} \mathrm{H}_{40}$ with six degrees of unsaturation. Four olefinic carbon signals were observed in the ${ }^{13} \mathrm{C}$ NMR spectrum of 4 , collectively indicating the tetracyclic nature of 4 . Further analysis of 2D NMR spectra illuminated that $\mathbf{4}$ possesses the identical carbon skeleton to that of variecolin (1) (Figure S1), and therefore, 4 is likely to be the biosynthetic precursor of 1 . The absolute configuration of 4 was deduced based on that of $\mathbf{1}$, and $\mathbf{4}$ was named variecoladiene (Figure 2C).
(A)



(C)



variecoladiene (4)
(B)

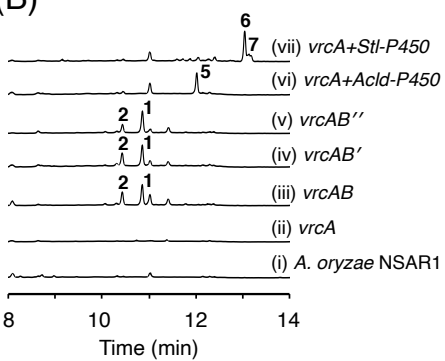

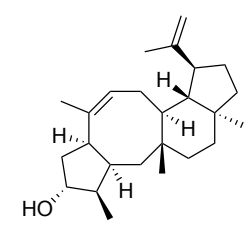

5

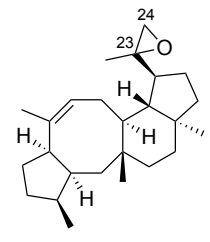

6: $23 R$
Figure 2. (A) GC-MS chromatograms of $A$. oryzae transformants. (B) HPLC chromatograms of the $A$. oryzae transformants. Chromatograms were monitored at $215 \mathrm{~nm}$. (C) Structures of the metabolites obtained in this study.

The cyclization of GFPP to form 4 should occur in a resemblant manner to that of astellifadiene (Figure 3 ), as previously discussed..$^{5 b}$ Thus, after the departure of the pyrophosphate group, $\mathrm{C}-\mathrm{C}$ bond formations occur at C-1/C-11 and C-10/C-14 to generate the bicyclic intermediate $4 \mathrm{a}^{+}$with $11-5$-fused ring system. Next, the five-membered ring undergoes ring expansion, which is concerted with the additional ring formation at C-14/C-18. The resultant 11-6-5-fused tricyclic cation $\mathbf{4 b}^{+}$is then neutralized by the deprotonation from $\mathrm{C}$ 24 to yield $4 c$. Subsequently, C-3 is reprotonated, which is followed by the $\mathrm{C}-\mathrm{C}$ bond formation at $\mathrm{C}-2 / \mathrm{C}-6$ to provide $4 \mathrm{~d}^{+}$harboring the 5-8-6-5-fused ring system; the occurrence of the reprotonation has been experimentally confirmed in the EvAS-catalyzed reaction. ${ }^{5 \mathrm{~b}} \mathrm{Fi}$ nally, the deprotonation from C-5 installs the double bond between C-7 and C-8 to complete the cyclization reaction. 


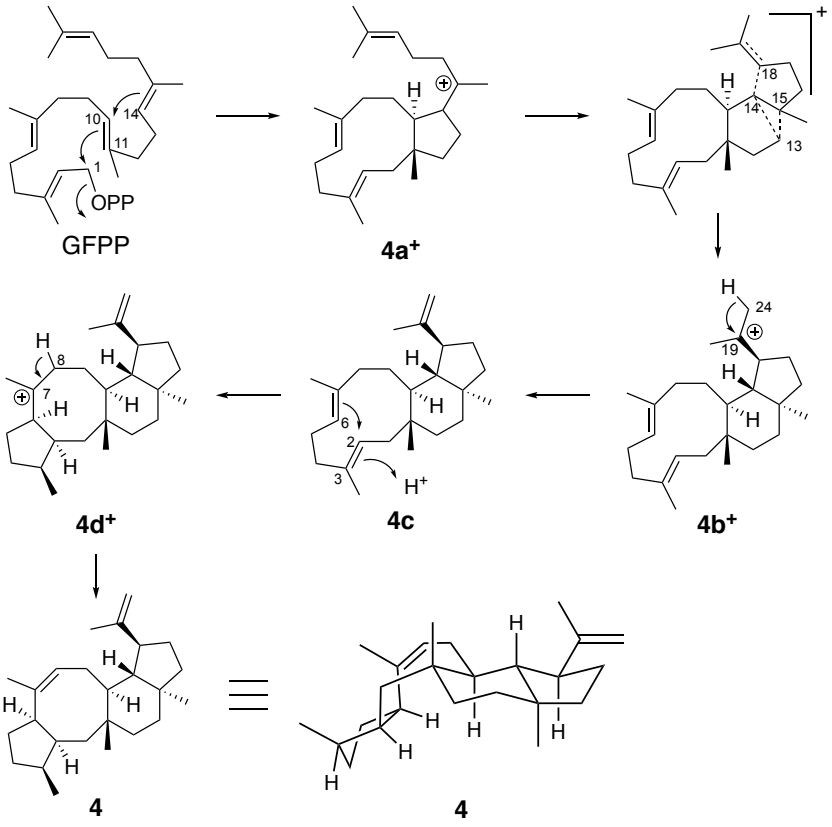

Figure 3. Proposed mechanism of the VrcA-catalyzed cyclization. The carbon atom numbering is in accordance with that for the EvAS-catalyzed reaction.

We then co-expressed the $\mathrm{P} 450$ gene $\operatorname{vrc} B$ along with the terpene synthase gene $\operatorname{vrc} A$ in $A$. oryzae, and consequently, two major peaks were observed in the HPLC analysis of the metabolites produced by the two gene-expressing strain (Figure $2 \mathrm{~B}$, trace iii). These two metabolites were purified, and the NMR analyses elucidated that they are variecolin (1) and variecolactone (2), respectively. In the course of the purification procedure, we noticed the presence of another minor metabolite, which was also isolated and identified as emericolin A (3). Thus, it is indicated that the $\mathrm{P} 450 \mathrm{VrcB}$ is solely responsible for the multiple oxidations at C-5 and C-20 positions. Collectively, it has been proven that the vrc cluster is indeed responsible for the variecolin biosynthesis, and heterologous production of 1 was successfully achieved.

Having established the heterologous production platform of variecolin (1), we then sought to derivatize the variecolin scaffold using the $A$. oryzae system. To this end, we collected known P450 genes involved in fungal di-/sesterterpenoid biosynthesis as well as uncharacterized $\mathrm{P} 450$ genes that are clustered with a potential sesterterpene synthase gene (Table S2 and Figures S2 and S3), and used them as genetic building blocks to construct artificial sesterterpenoid pathways. Each P450 gene was individually co-expressed with the sesterterpene synthase gene $\operatorname{vrc} A$, and among the 17 tested P450s, four P450s successfully yielded oxidized products of the hydrocarbon 4. Two P450s from Aspergillus violaceofuscus CBS $115571^{14}$ (designated as VrcB'; GenBank: PYI14930.1) and Aspergillus heteromorphus CBS $117.55^{14}$ (designated as VrcB"; GenBank: $\mathrm{XP}$ _025395330.1) exhibited the same product profile as VrcB (Figure $2 \mathrm{~B}$, trace iv and $\mathrm{v}$ ), and this observation would be reasonable, given the high sequence similarity between $\operatorname{VrcB}$ and the two P450s ( $89 \%$ and $79 \%$ amino acid identity, respectively). Intriguingly, the introduction of acldA-P45O involved in the biosynthesis of asperterpenol $\mathrm{B}^{4 \mathrm{~d}}$ afforded a new metabolite $\mathbf{5}$ (Figure $2 \mathrm{~B}$, trace vi), which was found to be a monooxygenated form of 4 by HR-MS analysis. The ${ }^{1} \mathrm{H}$ NMR spectrum of 5 revealed the presence of an oxymethine signal $\left(\delta_{\mathrm{H}} 4.01 \mathrm{ppm}\right)$, and accordingly, a signal for an oxygenated carbon $\left(\delta_{\mathrm{C}} 79.9 \mathrm{ppm}\right)$ was observed in the ${ }^{13} \mathrm{C} \mathrm{NMR}$ spectrum, altogether indicating that $\mathbf{5}$ is a hydroxylated form of 4 . Further analysis of the 2D NMR spectra confirmed that 5 harbors the $a$-hydroxy group at C-4 (Figures $2 \mathrm{C}$ and $\mathrm{S} 1$ ), as observed in asperterpenol B. Meanwhile, Stl-P450 responsible for the stellatic acid biosynthesis ${ }^{4 a}$ transformed 4 to two products 6 and 7 (Figure $2 \mathrm{~B}$, trace vii), both of which are isomers of 5 . The NMR spectra of 5 and 6 highly resemble each other, and the signals for the exomethylene at C-23/C-24 disappeared in both compounds. Alternatively, two doublet signals were newly observed at 2.5-2.7 ppm in the ${ }^{1} \mathrm{H}$ NMR spectra, and likewise, two signals at 55-61 ppm appeared in the ${ }^{13} \mathrm{C}$ NMR spectra, implying that the exomethylene was epoxidized by Stl-P450. The interpretation of the 2D NMR spectra then confirmed that 6 and 7 have the same planar structure with the epoxide at C-23/C-24 and only differ at the stereochemistry of C-23 position. The stereochemistry of the epoxide in $\mathbf{6}$ and $\mathbf{7}$ was determined to be $R$ and $S$, respectively, based on the NOESY correlations (Figures 2C and S1). It should be noted that the ${ }^{1} \mathrm{H}$ signal for $\mathrm{H}-9 \alpha$ of $7\left(\delta_{\mathrm{H}} 2.58\right.$ ppm) was observed at a much lower magnetic field than that of $6\left(\delta_{\mathrm{H}}\right.$ $2.18 \mathrm{ppm}$ ). This observation indicates that the epoxide oxygen of 7 is more proximately located to $\mathrm{H}-9 \alpha$ than in 6 , further supporting the deduced stereochemistry of the two compounds (Figure S1). Interestingly, Stl-P450 performs the oxidation of a methyl group to a carboxy group in the stellatic acid biosynthesis, which is distinct from the reaction that occurred on the variecolin scaffold.

Considering that variecolin (1) and its analogues exhibit diverse biological activities, it was expected that new metabolites obtained in this study could also have similar activities. All compounds, except for 3, were tested for cytotoxicity against human breast adenocarcinoma cell line MCF-7 and murine colon cancer cell line CT26 (Table 1 and Figures S4 and S5). The hydrocarbon 4 demonstrated only marginal cytotoxicity in the high micromolar concentration range, whereas the other compounds demonstrated improved anticancer activity in both cell lines. Remarkably, compound $\mathbf{5}$ exhibited comparable cytotoxicity to variecolin.

Table 1. Cytotoxicity of the metabolites obtained in this study determined by colorimetric MTT assay.

\begin{tabular}{ccc} 
& \multicolumn{2}{c}{$\mathrm{IC}_{50}[\mu \mathrm{M}]$} \\
Compound & MCF-7 & CT26 \\
\hline variecolin (1) & $1.4 \pm 0.3$ & $1.0 \pm 0.3$ \\
variecolactone (2) & $22 \pm 8$ & $14 \pm 3$ \\
variecoladiene (4) & $>500$ & $409 \pm 131$ \\
5 & $8 \pm 3$ & $2.9 \pm 0.4$ \\
6 & $146 \pm 82$ & $44 \pm 8$ \\
7 & $31 \pm 9$ & $16 \pm 5$
\end{tabular}

In conclusion, in this study, we have successfully achieved the heterologous production of variecolin (1), which has long been a challenging target for synthetic chemists. Furthermore, we have derivatized the variecolin scaffold by employing P450s from other fungal terpenoid pathways, and thus obtained three distinct biocatalysts that can efficiently oxidize the variecolin skeleton. Given that new variecolin analogues with different oxidative modifications all 
exhibited anticancer activity, the variecolin skeleton could be considered as a privileged scaffold for developing anticancer agents. Our study has demonstrated the usefulness of our simple synthetic biology strategy to obtain "unnatural" natural products. This approach could also be applied for the structural modification of other fungal sesterterpenoids, which would further diversify this class of natural products and possibly provide future drug leads with improved biological activities.

\section{ASSOCIATED CONTENT}

\section{Supporting Information}

A Supporting Information file is associated with this manuscript.

\section{AUTHOR INFORMATION}

\section{Corresponding Author}

*bhrkong@cityu.edu.hk (R.Y.C.K.)

*mbabak@cityu.edu.hk (M.V.B.)

*ymatsuda@cityu.edu.hk (Y.M.)

\section{Notes}

The authors declare no competing interest.

\section{ACKNOWLEDGMENT}

This work was performed for the iGEM 2021 Competition; financial support from the Department of Chemistry, City University of Hong Kong for the competition is greatly appreciated. We thank Prof. Katsuya Gomi (Tohoku University) and Profs. Katsuhiko Kitamoto and Jun-ichi Maruyama (The University of Tokyo) for the expression vectors and the fungal strain. We are grateful to Dr. Man-Kit Tse (City University of Hong Kong) for his assistance in NMR spectra acquisition. This work was in part supported by the Early Career Scheme grant from the Research Grants Council (RGC) of Hong Kong (Project No. 21300219 (Y.M)).

\section{REFERENCES}

(1) (a) Mitsuhashi, T.; Abe, I., Sesterterpenoids. In Progress in the Chemistry of Organic Natural Products 111, Kinghorn, A. D.; Falk, H.; Gibbons, S.; Kobayashi, J. i.; Asakawa, Y.; Liu, J.-K., Eds. Springer International Publishing: Cham, 2020; pp 1-79; (b) Li, K.; Gustafson, K. R., Sesterterpenoids: Chemistry, biology, and biosynthesis. Nat. Prod. Rep. 2021, 38, 1251-1281.

(2) Masi, M.; Dasari, R.; Evidente, A.; Mathieu, V.; Kornienko, A., Chemistry and biology of ophiobolin A and its congeners. Bioorg. Med. Chem. Lett. 2019, 29, 859-869.

(3) Chiba, R.; Minami, A.; Gomi, K.; Oikawa, H., Identification of ophiobolin $\mathrm{F}$ synthase by a genome mining approach: A sesterterpene synthase from Aspergillus clavatus. Org. Lett. 2013, 15, 594-597.

(4) (a) Matsuda, Y.; Mitsuhashi, T.; Quan, Z.; Abe, I., Molecular basis for stellatic acid biosynthesis: A genome mining approach for discovery of sesterterpene synthases. Org. Lett. 2015, 17, 4644-4647; (b) Narita, K.; Chiba, R.; Minami, A.; Kodama, M.; Fujii, I.; Gomi, K.; Oikawa, H., Multiple oxidative modifications in the ophiobolin biosynthesis: $\mathrm{P} 450$ oxidations found in genome mining. Org. Lett. 2016, 18, 1980-1983; (c) Huang, J.-H.; Lv, J.-M.; Wang, Q.-Z.; Zou, J.; Lu, Y.-J.; Wang, Q.-L.; Chen, D.-N.; Yao, X.S.; Gao, H.; Hu, D., Biosynthesis of an anti-tuberculosis sesterterpenoid asperterpenoid A. Org. Biomol. Chem. 2019, 17, 248-251; (d) Quan, Z.; Dickschat, J. S., Biosynthetic gene cluster for asperterpenols A and B and the cyclization mechanism of asperterpenol A synthase. Org. Lett. 2020, 22, 7552-7555; (e) Jiang, L.; Zhu, G.; Han, J.; Hou, C.; Zhang, X.; Wang, Z.; Yuan, W.; Lv, K.; Cong, Z.; Wang, X.; Chen, X.; Karthik, L.; Yang, H.; Wang, X.; Tan, G.; Liu, G.; Zhao, L.; Xia, X.; Liu, X.; Gao, S.; Ma, L.; Liu, M.; Ren, B.; Dai, H.; Quinn, R. J.; Hsiang, T.; Zhang, J.; Zhang, L.; Liu, X., Genome- guided investigation of anti-inflammatory sesterterpenoids with 5-15 transfused ring system from phytopathogenic fungi. Appl. Microbiol. Biotechnol. 2021, 105, 5407-5417.

(5) (a) Ye, Y.; Minami, A.; Mandi, A.; Liu, C.; Taniguchi, T.; Kuzuyama, T.; Monde, K.; Gomi, K.; Oikawa, H., Genome mining for sesterterpenes using bifunctional terpene synthases reveals a unified intermediate of di/sesterterpenes. J. Am. Chem. Soc. 2015, 137, 11846-11853; (b) Matsuda, Y.; Mitsuhashi, T.; Lee, S.; Hoshino, M.; Mori, T.; Okada, M.; Zhang, H.; Hayashi, F.; Fujita, M.; Abe, I., Astellifadiene: Structure determination by NMR spectroscopy and crystalline sponge method, and elucidation of its biosynthesis. Angew. Chem. Int. Ed. 2016, 55, 5785-5788; (c) Okada, M.; Matsuda, Y.; Mitsuhashi, T.; Hoshino, S.; Mori, T.; Nakagawa, K.; Quan, Z.; Qin, B.; Zhang, H.; Hayashi, F.; Kawaide, H.; Abe, I., Genome-based discovery of an unprecedented cyclization mode in fungal sesterterpenoid biosynthesis. J. Am. Chem. Soc. 2016, 138, 10011-10018; (d) Mitsuhashi, T.; Rinkel, J.; Okada, M.; Abe, I.; Dickschat, J. S., Mechanistic characterization of two chimeric sesterterpene synthases from Penicillium. Chem. Eur.J. 2017, 23, 10053-10057; (e) Narita, K.; Sato, H.; Minami, A.; Kudo, K.; Gao, L.; Liu, C.; Ozaki, T.; Kodama, M.; Lei, X.; Taniguchi, T.; Monde, K.; Yamazaki, M.; Uchiyama, M.; Oikawa, H., Focused genome mining of structurally related sesterterpenes: Enzymatic formation of enantiomeric and diastereomeric products. Org. Lett. 2017, 19, 6696-6699; (f) Gao, L.; Narita, K.; Ozaki, T.; Kumakura, N.; Gan, P.; Minami, A.; Liu, C.; Lei, X.; Shirasu, K.; Oikawa, H., Identification of novel sesterterpenes by genome mining of phytopathogenic fungi Phoma and Colletotrichum sp. Tetrahedron Lett. 2018, 59, 1136-1139; (g) Guo, J.; Cai, Y.-S.; Cheng, F.; Yang, C.; Zhang, W.; Yu, W.; Yan, J.; Deng, Z.; Hong, K., Genome mining reveals a multiproduct sesterterpenoid biosynthetic gene cluster in Aspergillus ustus. Org. Lett. 2021, 23, 1525-1529; (h) Jiang, L.; Zhang, X.; Sato, Y.; Zhu, G.; Minami, A.; Zhang, W.; Ozaki, T.; Zhu, B.; Wang, Z.; Wang, X.; Lv, K.; Zhang, J.; Wang, Y.; Gao, S.; Liu, C.; Hsiang, T.; Zhang, L.; Oikawa, H.; Liu, X., Genome-based discovery of enantiomeric pentacyclic sesterterpenes catalyzed by fungal bifunctional terpene synthases. Org. Lett. 2021, 23, 4645-4650; (i) Chen, R.; Jia, Q.; Mu, X.; Hu, B.; Sun, X.; Deng, Z.; Chen, F.; Bian, G.; Liu, T., Systematic mining of fungal chimeric terpene synthases using an efficient precursor-providing yeast chassis. Proc. Natl. Acad. Sci. USA 2021, 118, e2023247118.

(6) Christianson, D. W., Structural and chemical biology of terpenoid cyclases. Chem. Rev. 2017, 117, 11570-11648.

(7) Hensens, O. D.; Zink, D.; Williamson, J. M.; Lotti, V.J.; Chang, R. S.; Goetz, M. A., Variecolin, a sesterterpenoid of novel skeleton from Aspergillus variecolor MF138. J. Org. Chem. 1991, 56, 3399-3403.

(8) (a) Tezuka, Y.; Takahashi, A.; Maruyama, M.; Tamamura, T.; Kutsuma, S.; Naganawa, H.; Takeuchi, T. Novel antibiotics, AB5362-A, B, and $\mathrm{C}$, their manufacture, their use as fungicides, and Phoma species AB5362. Japan Patent JP 10045662, 1998; (b) Takahashi, H.; Hosoe, T.; Nozawa, K.; Kawai, K.-i., Two new sesterterpenes from the ascomycetous fungus Emericella purpurea. J. Nat. Prod. 1999, 62, 1712-1713; (c) Fujimoto, H.; Nakamura, E.; Okuyama, E.; Ishibashi, M., Immunomodulatory constituents from an ascomycete, Emericella aurantiobrunnea. Chem. Pharm. Bull. 2000, 48, 1436-1441; (d) Yoganathan, K.; Rossant, C.; Glover, R. P.; Cao, S.; Vittal, J. J.; Ng, S.; Huang, Y.; Buss, A. D.; Butler, M. S., Inhibition of the human chemokine receptor CCR5 by variecolin and variecolol and isolation of four new variecolin analogues, emericolins A-D, from Emericella aurantiobrunnea. J. Nat. Prod. 2004, 67, 1681-1684; (e) Joudaa, J.-B.; Fopossib, J.-L. D.; Mbazoaa, C. D.; Wandjia, J., Antibacterial activity of the major compound of an endophytic fungus isolated from Garcinia preussii. J. Appl. Pharm. Sci. 2016, 026-029; (f) Yodsing, N.; Lekphrom, R.; Sangsopha, W.; Aimi, T.; Boonlue, S., Secondary metabolites and their biological activity from Aspergillus aculeatus KKUCT2. Curr. Microbiol. 2018, 75, 513-518.

(9) (a) Piers, E.; Boulet, S. L., Total syntheses of the diterpenoids $( \pm$ )verrucosan-2 $\beta$-ol, $( \pm)$-neoverrucosan- $5 \beta$-ol, and $( \pm)$-homoverrucosan- $5 \beta$ ol. An approach to the synthesis of the sesterterpenoid variecolin. Tetrahedron Lett. 1997, 38, 8815-8818; (b) Molander, G. A.; Quirmbach, M. S.; Silva, L. F.; Spencer, K. C.; Balsells, J., Toward the total synthesis of 
variecolin. Org. Lett. 2001, 3, 2257-2260; (c) Li, K.; Wang, C.; Yin, G.; Gao, S., Construction of the basic skeleton of ophiobolin A and variecolin. Org. Biomol. Chem. 2013, 11, 7550-7558; (d) Krout, M. R.; Henry, C. E.; Jensen, T.; Wu, K.-L.; Virgil, S. C.; Stoltz, B. M., Wolff/Cope approach to the AB ring of the sesterterpenoid variecolin. J. Org. Chem. 2018, 83, 6995-7009.

(10) de Vries, R. P.; Riley, R.; Wiebenga, A.; Aguilar-Osorio, G.; Amillis, S.; Uchima, C. A.; Anderluh, G.; Asadollahi, M.; Askin, M.; Barry, K.; Battaglia, E.; Bayram, Ö.; Benocci, T.; Braus-Stromeyer, S. A.; Caldana, C.; Cánovas, D.; Cerqueira, G. C.; Chen, F.; Chen, W.; Choi, C.; Clum, A.; dos Santos, R. A. C.; Damásio, A. R. d. L.; Diallinas, G.; Emri, T.; Fekete, E.; Flipphi, M.; Freyberg, S.; Gallo, A.; Gournas, C.; Habgood, R.; Hainaut, M.; Harispe, M. L.; Henrissat, B.; Hildén, K. S.; Hope, R.; Hossain, A.; Karabika, E.; Karaffa, L.; Karányi, Z.; Kraševec, N.; Kuo, A.; Kusch, H.; LaButti, K.; Lagendijk, E. L.; Lapidus, A.; Levasseur, A.; Lindquist, E.; Lipzen, A.; Logrieco, A. F.; MacCabe, A.; Mäkelä, M. R.; Malavazi, I.; Melin, P.; Meyer, V.; Mielnichuk, N.; Miskei, M.; Molnár, Á. P.; Mulé, G.; Ngan, C. Y.; Orejas, M.; Orosz, E.; Ouedraogo, J. P.; Overkamp, K. M.; Park, H.-S.; Perrone, G.; Piumi, F.; Punt, P. J.; Ram, A. F. J.; Ramón, A.; Rauscher, S.; Record, E.; Riaño-Pachón, D. M.; Robert, V.; Röhrig, J.; Ruller, R.; Salamov, A.; Salih, N. S.; Samson, R. A.; Sándor, E.; Sanguinetti, M.; Schütze, T.; Sepčić, K.; Shelest, E.; Sherlock, G.; Sophianopoulou, V.; Squina, F. M.; Sun, H.; Susca, A.; Todd, R. B.; Tsang, A.; Unkles, S. E.; van de Wiele, N.; van Rossen-Uffink, D.; Oliveira, J.V.d. C.; Vesth, T. C.; Visser, J.; Yu, J.-H.; Zhou, M.; Andersen, M. R.; Archer, D. B.; Baker, S. E.; Benoit, I.; Brakhage, A. A.; Braus, G. H.; Fischer, R.; Frisvad, J. C.; Goldman, G. H.; Houbraken, J.; Oakley, B.; Pócsi, I.; Scazzocchio, C.; Seiboth, B.; vanKuyk, P. A.; Wortman, J.; Dyer, P. S.; Grigoriev, I. V., Comparative genomics reveals high biological diversity and specific adaptations in the industrially and medically important fungal genus Aspergillus. Genome Biol. 2017, 18, 28.

(11) Jouda, J.-B.; Fopossi, J.-L. D.; Kengne, F. M.; Djama Mbazoa, C.; Golz, C.; Strohmann, C.; Fogue, S. K.; Wandji, J., Secondary metabolites from Aspergillus japonicus CAM231, an endophytic fungus associated with Garcinia preussii. Nat. Prod. Res. 2017, 31, 861-869.
(12) Jin, F. J.; Maruyama, J.; Juvvadi, P. R.; Arioka, M.; Kitamoto, K., Development of a novel quadruple auxotrophic host transformation system by $\arg B$ gene disruption using ade $A$ gene and exploiting adenine auxotrophy in Aspergillus oryzae. FEMS Microbiol. Lett. 2004, 239, 79-85.

(13) (a) Matsuda, Y.; Wakimoto, T.; Mori, T.; Awakawa, T.; Abe, I., Complete biosynthetic pathway of anditomin: Nature's sophisticated synthetic route to a complex fungal meroterpenoid. J. Am. Chem. Soc. 2014, 136, 15326-15336; (b) Takino, J.; Kozaki, T.; Sato, Y.; Liu, C.; Ozaki, T.; Minami, A.; Oikawa, H., Unveiling biosynthesis of the phytohormone abscisic acid in fungi: Unprecedented mechanism of core scaffold formation catalyzed by an unusual sesquiterpene synthase. J. Am. Chem. Soc. 2018, 140, 12392-12395; (c) Tsukada, K.; Shinki, S.; Kaneko, A.; Murakami, K.; Irie, K.; Murai, M.; Miyoshi, H.; Dan, S.; Kawaji, K.; Hayashi, H.; Kodama, E. N.; Hori, A.; Salim, E.; Kuraishi, T.; Hirata, N.; Kanda, Y.; Asai, T., Synthetic biology based construction of biological activity-related library of fungal decalin-containing diterpenoid pyrones. Nat. Commun. 2020, 11, 1830; (d) Kahlert, L.; Bassiony, E. F.; Cox, R. J.; Skellam, E. J., Diels-Alder reactions during the biosynthesis of sorbicillinoids. Angew. Chem. Int. Ed. 2020, 59, 5816-5822; (e) Kahlert, L.; Villanueva, M.; Cox, R. J.; Skellam, E. J., Biosynthesis of 6-hydroxymellein requires a collaborating polyketide synthase-like enzyme. Angew. Chem. Int. Ed. 2021, 60, 11423-11429; (f) Wei, X.; Matsuda, Y., Unraveling the fungal strategy for tetrahydroxanthone biosynthesis and diversification. Org. Lett. 2020, 22, 1919-1923.

(14) Vesth, T. C.; Nybo, J. L.; Theobald, S.; Frisvad, J. C.; Larsen, T. O.; Nielsen, K. F.; Hoof, J. B.; Brandl, J.; Salamov, A.; Riley, R.; Gladden, J. M.; Phatale, P.; Nielsen, M. T.; Lyhne, E. K.; Kogle, M. E.; Strasser, K.; McDonnell, E.; Barry, K.; Clum, A.; Chen, C.; LaButti, K.; Haridas, S.; Nolan, M.; Sandor, L.; Kuo, A.; Lipzen, A.; Hainaut, M.; Drula, E.; Tsang, A.; Magnuson, J. K.; Henrissat, B.; Wiebenga, A.; Simmons, B. A.; Mäkelä, M. R.; de Vries, R. P.; Grigoriev, I. V.; Mortensen, U. H.; Baker, S. E.; Andersen, M. R., Investigation of inter- and intraspecies variation through genome sequencing of Aspergillus section Nigri. Nat. Genet. 2018, 50, 1688-1695. 